\title{
Social web and identity: a likely encounter
}

\author{
Thierry Nabeth
}

Received: 14 September 2009 / Accepted: 14 September 2009/Published online: 1 October 2009

(C) The Author(s) 2009. This article is published with open access at Springerlink.com

\begin{abstract}
The Web 2.0, with online social technologies such as social networking services, blogs, wikis, or microbloging, has brought the vision of the Internet as a social landscape in which people are engaged in a multitude of social activities. This editorial of the special issue 'Social Web and Identity' discusses the importance of identity in the context of the Social Web, introducing the different papers of this special issue and the different aspects associated to these online identities. The topics covered in this issue include how people define their identity in blogs and what is the articulation between online and offline identities in these systems. It also presents an article studying the privacy issues in online social networks and more specifically how these risks are perceived and how people can control their identity in this context. The next article compares privacy in two different categories of social systems (social network and collaborative workspace). Finally, another article discusses to what extent the current legislation, such the data protection regulations directive $95 / 46 / \mathrm{EC}$, is providing the right instrument for dealing with privacy issues.
\end{abstract}

Keywords Identity $\cdot$ Social web $\cdot$ Blogs $\cdot$ Social networking services

\section{Introduction: The rise of the social web, and of online identity}

The Social Web, and more generally the Web 2.0 phenomenon, has totally transformed our vision of the Web from one that was just dealing mainly with a huge amount of information, into a system for which one of the most important roles

T. Nabeth $(\bowtie)$

INSEAD, Bvd de Constance, 77305 Fontainebleau Cedex, France

e-mail: thierry.nabeth@insead.edu 
is to support the social process (Chi 2008). In the Social Web, individuals use a variety of tools such as blogs, wikis, social networking services, social bookmarking, microbloging, etc. to communicate with one another, to share opinion, to manage their social network, and more generally to conduct activities that are centred on people and not any longer on documents.

Of course, the new social software did not invent the use of the Internet to support this kind of communication. Many tools were used well before the Web 2.0 era for supporting social interaction such as email (which was actually one of the first Internet application), chat (with even special tools such as IRC), forums, electronic bulletin board and virtual communities (The WELL (Rheingold 1993), one the oldest and most famous virtual community was created in 1985), MUD (text-based multi-users games), and virtual worlds, to name a few. However, what makes the new tools and services different, and probably explains the reason for their success, is that they intervene at the whole social level, and not only the mere communication level. The Social Web provides the means to identify other people (who are only know indirectly or are perfect strangers), to assess the benefit of engaging with them into a social exchange and to continue the interaction. Indeed social exchange theory (Thibaut and Kelly 1959) states that people interact with others if they have good reasons for it. Social tools also have a role of informing of the activities of others, and reinforcing the sense of belonging, and therefore participation (Wandersman and Giamartino 1980). They also contribute to the establishment of trust between parties, another important factor in people participation (Tung et al. 2001).

In this perspective, a central component of the Social Web is the support for the definition and the construction of rich online identities. These identities consists of a patchwork of information of diverse origins and quality and which includes both information self declared by users in their online profiles (pseudonyms, ages, interest, etc.), information that can be inferred from their actions (people can express their opinion, and leave traces that are easily available), but also information explicitly declared by others (e.g. opinions stated about the person) or more explicitly observed (such as reputation and online social status).

Hence, the Social Web offers a number of mechanisms that contribute to the definition, construction and the functioning of these online identities that subsequently have a strong influence on the social process. These mechanisms include sophisticated user profiles typically found in online social networking services that are used to describe people identity at the individual level (with online CVs) or at the social level (who they know, and group affiliations). They also include different means of declaring their more informal identity, such as when they express their views in a personal blog. They also include socially translucent mechanisms making the social activity more visible (Erickson et al. 2002) and allowing the observation of people's actions, and know about their behaviour.

\section{Identity in the Social Web: questions and issues}

Online identity in the social web raises a number of questions and issues.

The first question is related to the form and the nature of these online identities. Identities in the social web can be found in a variety of forms in the different social 
tools: declared explicitly in the profiles of the online social sites; presented more implicitly via the postings of opinion in personal blogs that allow people to express their beliefs, in the reputation mechanisms systems that can be found in commerce site and that provide reputation indicators (Resnick et al. 2000), or in the social roles that emerge in systems such as Wikipedia. As will be indicated in a paper in this special issue, an element that can participate to online identity can start very early with the choice of a pseudonym. Online identity and offline identity may not also be totally disconnected from one another, but become two facets of a single 'blended' identity.

Second, these identities 'deal' with personal data, and represent a number of risks (Rosenblum 2007) that are related to the exposure of this data. For instance employers or prospective employers have been collecting information in personal blogs or social networking site about employees (a recent study has found that $45 \%$ of companies have adopted this practice (Eaton 2009)), and have used them to dismiss them (or deny them jobs) (Viégas 2005; Mannan and van Oorschot 2008). Yet at the same time, people have developed strategies to protect or manage their online identities by using pseudonyms or by constructing embellished identities. In the later case it has been demonstrated that the information present in profiles of online dating sites is not totally accurate, and for instance, people are known to lie as a way of generating a better impression (Toma et al. 2008). Of course this 'unreliability' of online identities can also apply in both direction and end users also have to learn not to trust them blindly. Besides, a number of legal instruments, such as law related to the protection of personal data, also exist that can applied in an online context in the case other methods have failed to resolve a situation.

\section{Understanding online identity in the Social Web}

This special issue about the Social Web and Identity tries to shed some light on the subject.

Blogging, which has represented one of the first social tools invented as part of Web 2.0, constitutes the context of the first two articles "Mick or Keith: Blended Identity of Online Rock Fans", by Andrea Baker (Baker 2009), and "Constructing academic alter-egos: Identity Issues in a Blog-based Community" by Vanessa Paz Dennen (Dennen 2009). The first paper discusses the "blended identity" of online rock fans to show that the standard dichotomy between anonymous and real life personas is an inadequate description of self-presentation in online communities. The second paper, which relies on a longitudinal ethnographic study, uses the context of an academic blogging community to explore how the elements constitute and contribute to a blogger's identity, the role of the pseudonyms, and how these identities are shaped and affected by participation in the larger blogging community to which they belong.

The third paper "Social networks and web 2.0: are users also bound by data protection regulations?" by Brendan Van Alsenoy, Joris Ballet, Aleksandra Kuczerawy (Van Alsenoy et al. 2009) examines the extent to which the existing legislation is already adequate to deal with privacy issues in the social web. More specifically it investigates the liability of users of social network sites under data 
protection and assesses the extent to which the current legal framework can sufficiently accommodate the new realities of web 2.0 and social networking applications.

The fourth paper, "Privacy Concerns and Identity in Online Social Networks", by Hanna Krasnova, Oliver Günther and Sarah Spiekermann (Krasnova et al. 2009) is about perception of risk and control of online identity in the context of the social web. Using focus groups and an empirical study, it first tries to understand privacyrelated concerns. It then examines the impact of these privacy concerns on the self-disclosure of information.

The last paper, "A Comparison of Privacy Issues in Collaborative Workspaces and Social Networks", by Martin Pekárek and Stephanie Pötzsch (Pekárek and Pötzsch 2009), makes a comparison, with regard to privacy threats of two of types of Web 2.0 applications - collaborative workspaces (Wikipedia) and social network sites (FaceBook). It finds that both of these systems suffer from the same privacy issues, and that one of the principal risk is related to the use of personal data in contexts other than the original and intended one. Its analysis suggests that a combination of technical, legal, and normative solutions should be considered to counter privacy issues.

Open Access This article is distributed under the terms of the Creative Commons Attribution Noncommercial License which permits any noncommercial use, distribution, and reproduction in any medium, provided the original author(s) and source are credited.

\section{References}

Baker A. Mick or Keith: Blended identity of online rock fans. Identity in the Information Society journal, Special Issue 'Social Web and Identity', 2009. doi:10.1007/s12394-009-0015-5

Chi Ed H. The social web: research and opportunities. IEEE Computer. 2008;41(9):88-91.

Dennen VP. Constructing academic alter-egos: identity issues in a blog-based community. Identity in the Information Society journal, Special Issue 'Social Web and Identity', 2009. doi:10.1007/s12394-0090020-8

Eaton K. If You're applying for a job, censor Your Facebook Page, FastCompany Wed Aug 19, 2009, http://www.fastcompany.com/blog/kit-eaton/technomix/if-youre-applying-job-censor-yourfacebook-page

Erickson T, Halverson C, Kellogg WA, Laff M, Wolf T. Social translucence: designing social infrastructures that make collective activity visible, communications of the ACM (Special issue on Community, ed. J. Preece) 2002. 45(4): 40-44.

Krasnova H, Günther O, Spiekermann S. Privacy concerns and identity in online social networks. identity in the information society journal, Special Issue 'Social Web and Identity', 2009.

Mannan M, van Oorschot PC. Privacy-enhanced sharing of personal content on the web. In Proceeding of the 17th international Conference on World Wide Web (Beijing, China, April 21-25, 2008). WWW '08. ACM, New York, NY, 487-496

Pekárek M, Pötzsch S. A comparison of privacy issues in collaborative workspaces and social networks. Identity in the Information Society journal, Special Issue 'Social Web and Identity', 2009. doi:10.1007/s12394-009-0016-4

Resnick P, Zeckhauser R, Friedman E, Kuwabara K. Reputation systems. Communications of the ACM 2000; 43(12): 45-48

Rheingold H. The virtual community, homesteading on the electronic frontier. Addison-Wesley; 1993

Rosenblum D. What anyone can know: the privacy risks of social networking sites. IEEE Security and Privacy. 2007;5(3):40-9. 
Toma C, Hancock JT, Ellison N. Separating fact from fiction: an examination of deceptive selfpresentation in online dating profiles. Pers Soc Psychol Bull. 2008;34:1023-36.

Thibaut JW, Kelley HH. The social psychology of groups. New York: Wiley; 1959.

Tung LL, Tan PLJ, Chia PJT, Koh YL. An empirical investigation of virtual communities and trust. Proceedings of the 22nd International Conference on Information Systems, 2001. pp. 307-320

Van Alsenoy B, Ballet J, Kuczerawy A. Social networks and web 2.0: Are Users also Bound by Data Protection Regulations?. Identity in the Information Society journal, Special Issue 'Social Web and Identity', 2009.

Viégas FB. Bloggers' expectations of privacy and accountability: An initial survey. Journal of ComputerMediated Communication 2005, 10(3); article 12.

Wandersman A, Giamartino G. Community and individual difference characteristics as influences on initial participation. Am J Community Psychol. 1980;8:217-28. 